\title{
A Study on the On-camera Value and Quality Requirements of the On-camera Correspondent and Reporter in the TV News
}

\author{
Qianqian $\mathrm{Wu}$ \\ College of Literature and Law \\ Nanyang Institute of Technology \\ Nanyang, China 473004
}

\begin{abstract}
With the rapid development of financial media, audiences have higher requirements on the timeliness, authenticity, and presence of news, which makes the live report of on-camera correspondent and reporter a crucial part of television news report. The on-camera correspondent realizes the value and significance of " $I$ ' $m$ in the field" by retelling, observing, analyzing, and commenting on the news scene, and enhances the liveliness, intimacy, authority, credibility, and humane care and emotional resonance of the TV news. At the same time, this form of linear transmission also imposes higher requirements on the personal image and business literacy of the reporters. An excellent on-site report not only requires that the reporter have good language skills, and the communication ability of paralanguage, but also have sensitivity to news, onsite observation, judgment of events, and control of emotions, etc.
\end{abstract}

Keywords-TV news; on-camera correspondent and reporter; value; quality

\section{INTRODUCTION}

Live report, as an important form of television news report, has been increasingly used by TV stations at all levels. This reporting method can well meet the audience's demands for "new" and "near" news. In all kinds of television news reports, the reporters are exposed to the scenes and the news spot, to present news facts to a broad audience, describe the details of events, comment on news progress, etc., thereby completing the purpose and significance of public opinion dissemination. This type of reporter is a key factor in TV news. They are the main body of live news on TV news, as well as the off-site hosts. We call such people "on-camera correspondent and reporter". The emergence of on-camera correspondent and reporter is the result of the fragmented and narrow broadcasting of China's broadcasting and television industry. As the division of labor in journalism becomes more and more detailed, the news forms of live reports rise in response to the time in the face of the increasingly complex news events and the diversified demands of the audience. As the on-camera correspondent and reporter are different from the hosts and announcers in the traditional sense, from the differences in functionality and division of labor, the job "reporter" is emerged. It should be said that with the participation of on-camera correspondent and reporter, the form of television news is more varied, the news content is fuller, and the programs are more attractive. For the research of on-camera correspondent and reporter, the industry and the academic circles have made some achievements. Based on this, this article starts from the appearance value of the reporters and discusses the basic qualifications that the reporters should have in television news reports, in order to promote the development and norms of the job on-camera correspondent and reporter.

\section{THE SIGNIFICANCE OF LIFE ON-CAMERA REPORT}

The English version of the word "出镜记者" is "on-camera correspondent and reporter", which means "the correspondent and reporter on the scene." Therefore, it can be inferred literally that the on-camera correspondent and reporter requires two conditions: first, the work of on-camera correspondent and reporter can't be separated from the camera; second, only being on the scene can be regarded as on-camera report. The scene here can be interpreted as the news spot. Especially the major news scene needs on-camera report. It can be seen that the on-camera correspondents has the following characteristics: first, in the process of the gradual maturity of television communication technology, the receptivity and receiving mode of public to news has been changed; second, in order to enhance the depth and vividness of news reports, it requires news workers go to the site of news events to report first-hand information. Third, some hosts with good news literacy and strong resilience began to go to the news site for real-time reporting. In summary, the birth of on-camera correspondents is caused by a variety of factors such as the development of television technology, the needs of the audience, and the development and changes of news events. Then, what significance and value does the on-camera correspondent have in the live report? The author will discuss in detail below.

\section{A. Enhancing the Sense of Presence}

The emergence of the job on-camera correspondent and reporter has broken the traditional broadcast pattern of screen and voice-over of television news. It began to directly report news facts to the audience, follow up on incidents, and make 
direct comments on news spot. This greatly enhances the sense of presence of television news. The on-camera correspondent and reporters "I am here" makes the news spot more authentic, allowing the audience to have an immersive and empathetic effect. On-camera correspondent and reporter can give the audience more intuitive guidance through the presentation, observation, interviews, and feelings in the news spot to make the news events tightly hold the audience's heart, so that their desire to watch further increases. In this sense, an on-camera correspondent and reporter does not merely represent an individual. She is also a kind of symbol and a kind of sound, which represents the camera group, the television station, and even some groups to make sound, making news reports have more authenticity and sense of presence.

\section{B. Enhancing the Authority and Credibility of News}

In traditional television news reports, there are is oncamera report section with reporters appearing on camera and the audience knows the news events through pictures and dubbing. Although this form can also reflect the authenticity and timeliness of the news, the effect of the news is greatly reduced. With the appearance of on-camera correspondent and reporter, more and more reporting forms have not only enriched the sensible and observable nature of television news, but more importantly enhanced the authority and credibility of television news. Especially the appearance of brand reporters on the spot is more able to achieve this effect. For example, the live reports of reporters who are familiar to the audience, such as Bai Yansong, Zhang Quanling, Chai Jing, Jiang Lin, etc., will undoubtedly give audiences a sense of "dating". The audiences see them in the TV news as seeing a benchmark, and will have a stronger understanding of the authenticity and authority of news events.

\section{Deepening the Content of News Reports}

The live report of on-camera correspondent and reporter can not only make the news more authentic and authoritative, but also deepen the content of the news. Reporters extend the depth and breadth of the news events at the scene through the ways of interviews and observation, so that the audience have a more direct and in-depth understanding of the news events. For example, in major events such as catastrophic news, the reporter's direct interviews with the parties or the masses at the scene can make the content of the whole news more stereoscopic and full, enabling the audience to understand and know news events more profoundly, systematically and intuitively and obtain more information through the pictures of interviews and the facial appearance and language expression of reporters, parties, masses and other individuals, so that the report of the whole news event becomes "alive", which is the effect that cannot be achieved by only relying on the narrator of the studio.

\section{Enriching the Form of News Report}

Traditional news reports usually take the two forms of introduction of studio host and picture and the picture plus or the voice-over and picture. Although some excellent studio host can express fluently, sound standard, describe the news picture with plump emotion, narrates the occurrence, the development, and the end news of event clearly, as well as launch the corresponding reviews or the deep comment, but they cannot get rid of this kind of monotonous report form. With the appearance of on-camera correspondent and reporter and TV station sending reporters to the scene of the incident, the whole news report is made more spiritual. While cooperating with the host of the studio, the live reporters make the program more visible and more profound to the audience through the active performance on the spot, the camera lens, and the communication with the interviewees.

\section{NECESSARY QUALITY OF ON-CAMERA CORRESPONDENT AND REPORTER}

The on-camera correspondent and reporter occupies a very important position in the news event report, which can make the news event have more sense of presence, authority, authenticity and credibility, and enrich the form of the program to a great extent and deepen the content of the program. An excellent on-camera correspondent and reporter can not only bring credibility, visibility, and audience ratings for the entire news program, but also let themselves "live" in the hearts of the audience to form the brand effect. Therefore, today when all levels and all kinds of television news programs are getting popular, what kind of reporters can occupy a favorable position in the live report, to improve the overall effect of the program?

\section{A. Ability to Judge News}

An on-camera correspondent and reporter belong to a journalist, so the job nature and professional literacy is one of the training goals of traditional journalism. In addition to the excellent appearance, standard mandarin and fluent language expression, the on-camera correspondent and reporters are required to have the basic news professional knowledge, the ability to judge the value of news events, the ability to understand the interviewees in depth and the ability of humanistic care, which is one of the main reasons why many broadcasters or hosts are not competent at this profession. Nowadays, as a part of the television news live report, the on-camera correspondent and reporter plays a more and more important role, especially in the major events or emergencies.

The special work environment and the on-camera way require the on-camera correspondent and reporter have the ability to quickly find news clues and quickly capture the "eyes" of news. On this basis, they can quickly integrate news information, conduct macro and micro thinking, accurately report news facts, flexibly response to site conditions, and appropriate comments on the progress of events, etc., striving to make clear the news facts in the shortest possible time, and convey the most important news points and most valuable news information to the audience. 


\section{B. The Ability to Control Emotions}

Moderately expressing emotions when reporting on the spot helps to increase the appeal and affinity because news is inevitably biased, including the reporter's emotional attitude. Appropriate use of various means by qualified journalists to express their emotional attitudes will not only make news reports more colorful, but will also give more humanistic care.

In the SARS report, when the reporter Wang Zhi saw the medical staff's deeds and work scenes, he was touched and wiped the tears with a bit of disguise. The momentary movement was recorded by the camera, which is called the model of live reporter who controls the emotion. However, some reporters have forgotten the professional identity and professional role of journalists when they "integrate" with the scene. Many reporters will face many people who are leaving or dying and often encounter grief-related news events. In interviews with these vulnerable groups, many journalists often can't control over their emotions. For example, in a live report of a "Korean plane crash", when a reporter of Phoenix station interviewed the families of the victims, he cried over at the scene with their families because of excessive sadness. In this interview, in addition to the plot of crying, the audience did not get more on-site information.

The enlightenment from these two cases is that the sentimental attitude of the on-camera correspondent and reporter should not only be appropriate, but also be expressed properly and moderately. This is so-called appropriate emotional attitude. Because the on-camera report is to record news events, state the development of events, and comment on the impact of events, it is not the reporter's speech full of emotions. Therefore, when expressing emotions, they should be subtle, clever, and stop at where it should, and they should be able to adjust their emotions timely and correctly to restore calm as soon as possible without forgetting their own identity and role.

\section{Creative Abilities for Audio Language}

The live reports belong to linear communication and the news information is fleeting, so there is no chance for going back. Once the connection between the studio and the reporter is successful, it will start reporting directly. In the specific report scene, reporter's impromptu oral expression is required, since there is no suggestion of the manuscript, which requires the reporter to practice the basic skills of organizing language, and fluency is naturally a basic requirement for the audible language of reporters. In addition, attention should also be paid to the ability to describe on-site news events. This description should not only make the incident presented logically, but also have a detailed description of the scene, which puts higher requirements on the reporter's observation ability. At the same scene, some reporters can make reporting plump and very infectious, while some reporters dryly say a few reports similar to news leads, without any value for on-camera report in fact. This requires reporters to practice in the usual, accumulate news knowledge in daily work, and train their pronunciation of Mandarin and language expressing skills, to lay a solid foundation for the smooth conduct of live reports.

\section{Design Capabilities for Paralanguage}

In the live reports, the paralanguage also occupies a very important role. The attitude, movement, eye contact, and dress of the reporter, including the choice of the scene, all determine the success of the report to some extent. Body language includes both movement and expression. The reporter's movement should be appropriately converted according to the language content, but the amplitude should not be too large. The timely rise, bow, and shaking one's head are conducive to the presentation of the overall beauty in reporters' reporting and interviewing; natural and determined facial expressions can make news more convincing and authoritative, making it easier to convince the viewers. The dignified and capable image is also necessary for the on-camera correspondent and reporter. In the live report, the reporter should pay attention to the news event rather than his own personal image. This requires that the reporter's wearing, makeup, and hairstyle should be consistent with the scene, which is conducive to the infectious power of the scene and can match the news event. The choice of scene is also very important to the reporter's report, since the proper scene can do its bits to the success of the report, while the chaotic scene which has nothing to do with the news event will also lead to the failure of the report to a certain extent. Especially in the scene of the major news event or the sudden news event, the choice of the scene is particularly important.

\section{CONCLUSION}

Live reporting is an important part of television news. The appearance of an on-camera correspondent and reporter can not only make the program form richer and the sense of the scene stronger, but also reflect the humanistic concern and enhance the audience's conviction A successful live report cannot be separated from the reporter's solid news professional basic skills, comfortable emotional control, fluent sound language, and appropriate auxiliary language and so on, which put forward higher requirements for the professional requirements and professional positioning of the on-camera correspondent and reporter. It can make the news report win more audience and make the communication effect realize the optimization to give full play to the sharp weapon of the on-camera correspondent and reporter.

\section{REFERENCES}

[1] Song Xiaoyang. Guide for live report of on-camera correspondent and reporter [M]. Beijing: China Radio Film and Television Press, 2008.

[2] Wang Nan. The Spreading Skills of Nonverbal Symbols for oncamera correspondent and reporter [J]. Voice and Screen World, 2014 (2).

[3] Zheng Yu. Journalist Role and Social Responsibility [J]. Contemporary Communications, 2007. (1). 